\title{
A enfermeira obstétrica no cuidado ao parto domiciliar planejado: revisão integrativa
}

\section{Obstetric nurses and healthcare in planned home childbirth: an integrative review}

\section{La enfermería obstétrica en el cuidado al parto domiciliario planeado: revisión integrativa}

Recebido: 07/11/2018

Aprovado: 19/05/2019

Publicado: 01/07/2019
Silvana Regina Rossi Kissula Souza ${ }^{1}$ Miriam Cristiane de Jesus Drygla Oliveira² Juliane Dias Aldrighi ${ }^{3}$ Larissa de Oliveira Peripolli4 Marilene Loewen Wall 5

O objetivo deste estudo foi identificar, na literatura científica, as práticas de cuidado realizadas pela enfermeira obstétrica no Parto Domiciliar Planejado. Trata-se de uma revisão integrativa realizada nas bases de dados MEDLINE, LILACS e BDENF, considerando o período de 2005 a 2015 e realizado em dezembro de 2015. Foram encontrados 139 artigos, dos quais oito atenderam aos critérios de inclusão, sendo esses selecionados e analisados por meio da análise temática. Os estudos evidenciaram quatro categorias: Humanização do parto; Práticas de Cuidado das Enfermeiras Obstétricas; Responsabilidade Profissional e Desfecho do Parto Domiciliar. O parto domiciliar planejado é uma modalidade de assistência humanizada e as práticas de cuidado realizadas pela enfermeira obstétrica contribuem para um trabalho de parto com desfecho favorável e satisfatório para as parturientes. Essa profissional deve conhecer e atuar conforme sua legislação para que o cuidado prestado seja seguro e livre de dano à mulher e ao bebê.

Descritores: Parto domiciliar; Parto humanizado; Parto normal; Enfermeiras Obstétricas; Enfermagem Obstétrica.

This study aimed to identify, in scientific literature, what are the healthcare practices carried out by obstetric nurses in Planned Home Childbirths. This is an integrative review carried out in the databases MEDLINE, LILACS and BDENF, analyzing the period from 2005 to 2015, and performed in December 2015. The research found 139 articles, 8 of which were according to the inclusion criteria. They were selected and analyzed using a thematic analysis. The studies revealed four categories: Childbirth Humanization; Healthcare Practices of Obstetric Nurses; Professional Responsibility; and Home Birth Outcome. Home births are a type of humanized assistance, and the healthcare practices of the obstetric nurse increase the chance of favorable and satisfactory outcome for the parturient regarding delivery. Also, this professional may help and act according to the law, for the healthcare offered to be safe and bring no harm to the woman and the baby.

Descriptors: Home childbirth; Humanizing delivery; Natural childbirth; Nurse Midwives; Obstetric Nursing.

El objetivo de este estudio fue identificar en la literatura científica las prácticas de cuidado realizadas por la enfermera obstétrica en el Parto Domiciliario Planeado. Se trata de una revisión integrativa realizada en las bases de datos MEDLINE, LILACS y BDENF considerando el periodo de 2005 a 2015 y realizado en diciembre de 2015. Fueron encontrados 139 artículos, de los cuales ocho atendieron a los criterios de inclusión, siendo estos seleccionados y analizados por medio del análisis temático. Los estudios evidenciaron cuatro categorías: Humanización del parto; Prácticas de Cuidado de las Enfermeras Obstétricas; Responsabilidad Profesional y Desenlace del Parto Domiciliario. El parto domiciliario planeado es una modalidad de asistencia humanizada y las prácticas de cuidado realizadas por la enfermera obstétrica contribuyen a un trabajo de parto con desenlace favorable y satisfactorio para las parturientas. Y esta profesional debe conocer y actuar conforme su legislación para que el cuidado prestado sea seguro y libre de daño a la mujer y al bebé.

Descriptores: Parto domiciliario; Parto humanizado; Parto normal; Enfermeras Obstetrices; Enfermería Obstétrica.

\footnotetext{
1. Enfermeira Obstétrica. Mestre em Engenharia de Produção. Doutora em Ciências. Coordenadora do Curso de Especialização em Enfermagem Obstétrica Rede Cegonha/UFMG/UFPR. Professora pelo Programa de Pós Graduação em Enfermagem da Universidade Federal do Paraná (PPGE-UFPR), Curitiba, PR, Brasil. ORCID: 0000-0002-1679-4007 E-mail: skissula@ufpr.br

2. Enfermeira. Departamento de Enfermagem da UFPR, Curitiba, PR, Brasil. ORCID: 0000-0003-3738-4338 E-mail: miriam_drygla@hotmail.com

3. Enfermeira. Especializanda em Gestão em Saúde. Mestre em Enfermagem. 0RCID: 0000-0002-9270-7091 E-mail: juliane.aldrighi@gmail.com

4. Enfermeira Obstétrica do Hospital de Clínicas da Universidade Federal do Paraná (HC-UFPR). Mestranda em Enfermagem pelo Programa de Pós-Graduação em Enfermagem (PPGE) da UFPR, Curitiba, PR, Brasil. ORCID: 0000-0003-0582-874X E-mail: lperipolli@gmail.com 5. Enfermeira Obstétrica. Mestre e Doutora em Enfermagem. Professora pelo PPGE-UFPR, Curitiba, PR, Brasil. ORCID: 0000-0003-1839-3896 E-mail: wall@ufpr.br
} 


\section{INTRODUÇÃO}

A té o século XVIII, o parto era realizado por parteiras, mulheres com conhecimentos empíricos que realizavam os cuidados à mãe e ao recémnascido em domicílio. Entretanto, no final do século XIX, a medicina iniciou a transformação do parto em um evento controlado e, pouco a pouco, o parto domiciliar foi sendo extinto ${ }^{1}$. Dessa forma, esse fenômeno, que usualmente era realizado em ambiente particular e perto da família, começou a ocorrer em instituições de saúde, ou seja, em locais públicos e longe dos familiares, submetendo as mulheres a intervenções que contribuíram para a elevação das taxas de cesáreas e, consequentemente, para o aumento da morbimortalidade materna e perinatal ${ }^{2}$.

O parto domiciliar ainda é alvo de críticas e resistência por parte de mulheres e profissionais. Essa insegurança se dá pelo medo de complicações advindas de um parto malsucedido, que no ideário leigo não aconteceria se a mulher estivesse parindo em um ambiente hospitalar. No entanto, mesmo no hospital o parto não é totalmente seguro, já que pode haver intercorrências, inclusive devido a intervenções desnecessárias, às quais, muitas vezes, as parturientes estão expostas ${ }^{3}$.

Desse modo, apesar das evidências científicas nacionais e internacionais mostrarem que o modelo atual de parto não é ideal, ele continua acontecendo devido à história da obstetrícia, do processo de institucionalização do nascimento, da supervalorização das tecnologias, da medicalização e da mercantilização das práticas em saúde.

0 parto, mesmo sendo domiciliar, deve ser realizado com todos os cuidados de segurança possíveis, tais como critérios de seleção, ambiente devidamente higienizado, materiais e equipamentos caso haja a necessidade de alguma intervenção, hospital de referência de fácil acesso, equipe qualificada e preparada para reconhecer precocemente as complicações e transporte rápido, caso haja necessidade ${ }^{3}$. Além de o parto domiciliar ser tão seguro quanto o parto hospitalar, ele é menos oneroso para o Estado e tem se mostrado uma experiência bem mais gratificante para as parturientes e seus familiares, justificando, assim, o incentivo do governo para sua realização nos países desenvolvidos ${ }^{1}$.

O Ministério da Saúde (MS) vem incentivando a atuação da enfermeira obstétrica no parto, pois a formação dessa profissional prevê a realização de partos de baixo risco sem distócia, desde que o ambiente apresente condições mínimas para sua realização. A Resolução do COFEN n. $516 / 2016^{4}$, que dispõe sobre a atuação de enfermeiros na assistência às gestantes, parturientes e puérperas, respalda a Enfermeira Obstetra e a Obstetriz a exercerem todas as atividades de enfermagem na área de obstetrícia. E, segundo Nota Oficial n. 001/2012/ASCOM 5 , de maio de 2012, a Enfermeira Obstetra tem competência científica, técnica e legal para o atendimento ao parto domiciliar.

Estudos ${ }^{6,7}$ demonstram que mulheres assistidas por enfermeiras obstetras têm menor chance de hospitalização antenatal, menor risco de analgesia regional, de episiotomia e parto instrumental, maior chance de parto vaginal espontâneo, de sensação de controle durante o nascimento e de iniciar o aleitamento materno precocemente, gerando, dessa maneira, uma alta taxa de satisfação materna.

Diante do exposto, a relevância deste estudo se justifica pela importância do tema, dado o avanço internacional da prática de partos domiciliares realizados por enfermeiras obstétricas e por ser um assunto ainda fadado ao mítico e com pouco conhecimento científico. Nesse sentido, o objetivo deste estudo foi identificar, na literatura científica, as práticas de cuidado realizadas pela enfermeira obstétrica no Parto Domiciliar Planejado.

\section{MÉTODO}

Trata-se de uma revisão integrativa da literatura nacional e internacional. Esse tipo de estudo pode ser definido como aquele em que $o$ autor realiza a síntese e uma análise do conhecimento científico já produzido sobre o tema investigado ${ }^{8}$.

A metodologia das revisões integrativas envolve seis etapas: a) Selecionar as hipóteses ou questões da revisão; b) Demonstrar a pesquisa a ser revista; c) Representar as características do estudo e suas constatações: a representação das características deve ser análoga quanto à reportação dos dados e de coleta de dados; d) Analisar as constatações: exame e análise de dados primários; e) Interpretar os resultados: é comparável com discussão dos resultados e implicações retiradas em pesquisas primárias; f) Reportar a revisão: deve-se incluir informações suficientes para que o leitor possa analisar criticamente as evidências ${ }^{8}$.

$\mathrm{Na}$ primeira etapa, buscou-se a identificação do tema e a seleção da questão norteadora: Quais são as práticas de cuidado realizadas pela enfermeira obstétrica no Parto Domiciliar Planejado?

Quanto à segunda etapa, a estratégia de identificação e seleção dos estudos foi a busca de publicações indexadas nas seguintes bases de dados: Base de Dados em Enfermagem (BDENF), Literatura Latino-Americana e do Caribe em Ciências da Saúde (LILACS) e Medical Literature and Retrivial System on Line 
(MEDLINE) no Portal da Biblioteca Virtual em Saúde (BVS).

Foram adotados os seguintes critérios de inclusão: artigos de pesquisa com textos completos disponíveis online; publicados entre 2005 e 2015; que apresentassem indicações das práticas de cuidado realizadas pela enfermeira obstétrica em parto domiciliar planejado no resumo; publicados em português ou inglês; e artigos que contivessem em seus títulos os seguintes descritores: parto humanizado, parto normal, parto domiciliar, enfermeiras obstétricas e enfermagem obstétrica. 0 critério de exclusão foi: artigos que, mesmo relacionados à temática proposta, não atendessem ao objetivo da pesquisa. As publicações que se encontravam indexadas em mais de uma base de dados foram selecionadas na primeira busca, que foi realizada em dezembro de 2015.

Utilizou-se como estratégia de busca: Parto domiciliar AND (instance: "regional") AND (db:("LILACS" OR "BDENF") AND mj:("Parto Domiciliar" OR "Enfermagem Obstétrica" OR "Parto Normal" OR "Parto Humanizado" OR "Enfermeiras Obstétricas") AND type:("article") Parto domiciliar AND (instance: "regional") AND (fulltext:("1") AND db:("MEDLINE") AND mi:("Parto Domiciliar" OR "Enfermagem Obstétrica" OR "Parto Normal" OR "Enfermeiras Obstétricas" OR
"Parto Humanizado") AND la:("pt") AND type:("article").

$\mathrm{Na}$ terceira e quarta etapas, após a obtenção dos estudos, os resumos foram analisados e avaliados, e as produções que atenderam aos critérios de inclusão estabelecidos foram selecionadas. Os artigos que fizeram parte desta revisão integrativa foram lidos de forma minuciosa, para que não fossem perdidos aspectos importantes para a organização, imersão das temáticas e confecção da redação da pesquisa.

A quinta etapa consistiu na discussão e interpretação dos resultados a partir da análise temática. A partir dessa análise, constatou-se que alguns artigos continham mais de um tema em comum. Assim, compuseram mais de uma categoria. A sexta etapa deu-se com a apresentação das evidências encontradas.

\section{RESULTADOS}

A considerar os critérios instituídos, oito artigos foram selecionados, conforme demonstra o Quadro 1. Dentre os estudos encontrados, um é um artigo científico internacional representado pela Holanda, e os outros sete são brasileiros. Os anos de publicação variaram de 2008 a 2015, ocorrendo o maior número em 2014, com três artigos. Dos oito artigos, cinco foram extraídos da base de dados LILACS, dois da BDENF e um da MEDLINE.

Quadro 1. Seleção dos artigos de pesquisa nas bases de dados LILACS, BDENF e MEDLINE entre 2005 e 2015. Curitiba, PR, Brasil, 2017.

\begin{tabular}{|l|c|c|c|c|c|c|c|}
\hline Bases & $\begin{array}{c}\text { Produção } \\
\text { encontrada }\end{array}$ & $\begin{array}{c}\text { Não aborda a } \\
\text { temática }\end{array}$ & Repetido & $\begin{array}{c}\text { Fora do } \\
\text { critério de } \\
\text { tempo }\end{array}$ & $\begin{array}{c}\text { Não disponível } \\
\text { onão é artigo } \\
\text { de pesquisa }\end{array}$ & $\begin{array}{c}\text { Total } \\
\text { selecionados }\end{array}$ \\
\hline LILACS & 39 & 20 & 10 & 2 & - & 2 & 5 \\
\hline BDENF & 24 & 11 & 11 & - & - & - & \\
\hline MEDLINE & 76 & 66 & 5 & - & 4 & - & 1 \\
\hline TOTAL & 139 & 97 & 26 & 2 & 4 & 1 & 8 \\
\hline
\end{tabular}

o Quadro 2 mostra os artigos selecionados conforme título, ano, país, base de dados, objetivo, delineamento e principais resultados.

Após a leitura dos estudos, emergiram temas comuns, que foram organizados em quatro categorias: Humanização do parto; Práticas de Cuidado das Enfermeiras Obstétricas; Responsabilidade Profissional; e Desfecho do Parto Domiciliar.

\section{DISCUSSÃO}

\section{Humanização do parto}

Temas sobre humanização do parto foram descritos em três estudos, e sugerem que durante o parto as intervenções utilizadas sejam mínimas, reduzindo assim o uso excessivo de tecnologias. 0 ambiente deve ser seguro, possibilitar privacidade, atendimento digno e de qualidade, conforto e liberdade de escolha ${ }^{9-11}$.

Dessa maneira, políticas públicas foram formuladas para que se concedesse à mulher $o$ direito de ter um parto conforme suas necessidades e preferências, com um cuidado individualizado no qual suas crenças, valores e cultura sejam respeitados ${ }^{9}$.

Outro estudo revela que o parto domiciliar resgatou a humanização, bem como a autonomia e o protagonismo da mulher, pois, dessa forma, ela pode fazer escolhas, expressar sentimentos, estar com sua família, usufruir de um ambiente calmo e harmonioso, e estar livre de ruídos e luzes. Todas essas situações, aliadas ao estímulo e ao apoio que a mulher recebe, auxiliam na produção de hormônios que favorecem o trabalho de parto e parto, proporcionando assim uma evolução fisiológica adequada ${ }^{10}$.

Ainda nessa categoria, um estudo afirma que intervenções sem efeitos colaterais, apoio e parto em piscinas são ações que promovem a humanização e auxiliam as mulheres a obter uma boa evolução durante o trabalho de parto e parto ${ }^{11}$. 
Quadro 2. Estudos incluídos na revisão integrativa. Curitiba, PR, Brasil, 2017.

\begin{tabular}{|c|c|c|c|c|}
\hline Título & $\begin{array}{c}\text { Ano/ } \\
\text { País/ } \\
\text { Base de } \\
\text { dados } \\
\end{array}$ & Objetivo & Delineamento & Principais resultados \\
\hline $\begin{array}{|lr|}\text { A escolha pelo } \\
\text { parto domiciliar: } \\
\text { história de vida de } \\
\text { Mulheres r que } \\
\text { vivenciaram esta } \\
\text { experiência9 }\end{array}$ & $\begin{array}{c}2008 \\
\text { Brasil } \\
\text { LILACS }\end{array}$ & $\begin{array}{l}\text { Analisar os fatores que } \\
\text { influenciaram a escolha } \\
\text { pelo parto domiciliar } \\
\text { assistido por enfermeira } \\
\text { obstetra. }\end{array}$ & Qualitativo & $\begin{array}{l}\text { O vínculo entre a enfermeira obstétrica e } \\
\text { sua cliente, bem como o respeito por suas } \\
\text { escolhas, expectativas e cultura } \\
\text { proporcionaram } \quad \text { segurança } \\
\text { confiabilidade as mulheres. }\end{array}$ \\
\hline $\begin{array}{l}\text { A percepção dos } \\
\text { profissionais sobre } \\
\text { a assistência ao } \\
\text { parto domiciliar } \\
\text { planejado }{ }^{10}\end{array}$ & $\begin{array}{c}2013 \\
\text { Brasil } \\
\text { BDENF }\end{array}$ & \begin{tabular}{|lr} 
Compreender & $\mathrm{a}$ \\
percepção & dos \\
profissionais & no \\
acompanhamento & do \\
parto & domiciliar \\
planejado &
\end{tabular} & Qualitativo & $\begin{array}{l}\text { A análise revelou que o domicílio, } \\
\text { enquanto local de assistência, possibilita o } \\
\text { protagonismo da mulher e da família. }\end{array}$ \\
\hline $\begin{array}{l}\text { Change in primary } \\
\text { midwife-led care } \\
\text { in the Netherlands } \\
\text { in 2000-2008: a } \\
\text { descriptive study } \\
\text { of caesarean } \\
\text { sections and other } \\
\text { interventions } \\
\text { among 789,795 } \\
\text { low risk births }{ }^{11}\end{array}$ & $\begin{array}{c}2014 \\
\text { Holanda } \\
\text { MEDLINE }\end{array}$ & $\begin{array}{l}\text { Investigar se o aumento } \\
\text { dos atendimentos por } \\
\text { parteiras na Holanda } \\
\text { levou a um aumento nas } \\
\text { cesáreas. }\end{array}$ & Quanti & $\begin{array}{l}\text { A proporção de mulheres que deram à luz } \\
\text { em hospital sob o cuidado de obstetras } \\
\text { aumentou entre } 2000 \text { e } 2008 \text { e o parto } \\
\text { vaginal diminuiu tanto para as mulheres } \\
\text { nulíparas como para as multíparas. }\end{array}$ \\
\hline $\begin{array}{l}0 \text { parto assistido } \\
\text { por enfermeira } \\
\text { obstetra: } \\
\text { perspectivas } \\
\text { controvérsias }^{12}\end{array}$ & $\begin{array}{c}2010 \\
\text { Brasil } \\
\text { LILACS }\end{array}$ & $\begin{array}{l}\text { Apresentar conflitos } \\
\text { existentes na assistência } \\
\text { ao parto por enfermeiro } \\
\text { obstetra e propor formas } \\
\text { de minimizá-los. }\end{array}$ & Qua & $\begin{array}{l}\text { A assistência ao parto, inicialmente } \\
\text { domiciliar e depois institucional, trouxe o } \\
\text { intervencionismo nessa atividade. o } \\
\text { aspecto social e humano do nascimento } \\
\text { foi minimizado. Encontrou-se forte } \\
\text { ligação entre enfoque de humanização do } \\
\text { parto e sua assistência por enfermeiro. }\end{array}$ \\
\hline $\begin{array}{lrr}\text { Parto } & \text { natural } \\
\text { domiciliar: } & \text { um } \\
\text { poder da } & \text { natureza } \\
\text { feminina } & \text { e } & \text { um } \\
\text { desafio } & \text { para } & \text { a } \\
\text { enfermagem } & \\
\text { obstétrica13 }^{13}\end{array}$ & $\begin{array}{c}2014 \\
\text { Brasil } \\
\text { BDENF }\end{array}$ & $\begin{array}{|lrr|}\text { Identificar } & \text { os } & \text { motivos } \\
\text { que levaram } & \text { as mulheres } \\
\text { a optarem } & \text { pelo parto } \\
\text { domiciliar; } & \text { avaliar } & \text { a } \\
\text { assistência } & \text { obstétrica } \\
\text { recebida } & & \text { pelas } \\
\text { parturientes } & \text { em } & \text { seus } \\
\text { domicílios. } & & \end{array}$ & 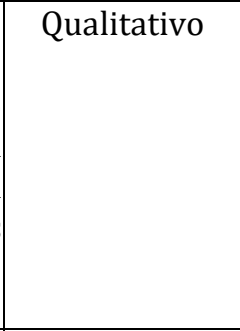 & $\begin{array}{l}\text { A motivação para a escolha de um parto } \\
\text { fora do modelo institucionalizado está } \\
\text { relacionada a multifatores como } \\
\text { personalidade, estilo de vida, visão de } \\
\text { mundo e experiências vivenciadas com } \\
\text { seus ascendentes. }\end{array}$ \\
\hline \begin{tabular}{|l|} 
A \\
responsabilidade \\
profissional na \\
assistência \\
parto: discursos de \\
enfermeiras \\
obstétricas $^{14}$ \\
\end{tabular} & $\begin{array}{c}2012 \\
\text { Brasil } \\
\text { LILACS }\end{array}$ & $\mid \begin{array}{lr}\text { Identificar } & \text { o } \\
\text { conhecimento } & \text { das } \\
\text { enfermeiras obstétricas } \\
\text { em relação } & \text { à } \\
\text { responsabilidade } & \\
\text { profissional } & \text { na } \\
\text { assistência ao parto. } & \\
\end{array}$ & $\begin{array}{l}\text { Qualitativo/Ex } \\
\text { ploratório }\end{array}$ & $\begin{array}{l}\text { Verificou-se que as enfermeiras conhecem } \\
\text { pouco a respeito das repercussões legais } \\
\text { do erro. }\end{array}$ \\
\hline 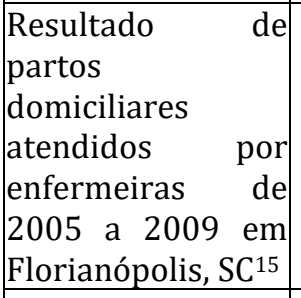 & $\begin{array}{c}2012 \\
\text { Brasil } \\
\text { LILACS }\end{array}$ & $\begin{array}{l}\text { Avaliar os resultados } \\
\text { obstétricos e neonatais } \\
\text { dos partos domiciliares } \\
\text { planejados assistidos por } \\
\text { enfermeiras obstétricas. }\end{array}$ & Quantitativo & $\begin{array}{l}\text { Os resultados indicam que o parto } \\
\text { domiciliar é seguro. }\end{array}$ \\
\hline \begin{tabular}{|l|} 
Partos \\
domiciliares \\
planejados \\
assistidos por \\
enfermeiras \\
obstétricas: \\
transferências \\
maternas \\
neonatais $^{16}$
\end{tabular} & $\begin{array}{c}2013 \\
\text { Brasil } \\
\text { LILACS }\end{array}$ & \begin{tabular}{|lrrr} 
Descrever & a & taxa & e as \\
causas de & transferência \\
intraparto & de & mulheres \\
assistidas & no & domicílio \\
por r & enfermeiras \\
obstétricas & e r os \\
desfechos & & desses \\
nascimentos no hospital \\
de referência.
\end{tabular} & $\begin{array}{l}\text { Quantitativo/ } \\
\text { Exploratório } \\
\text { descritivo }\end{array}$ & $\begin{array}{l}\text { O parto domiciliar planejado assistido por } \\
\text { enfermeiras obstétricas, com protocolo } \\
\text { assistencial, apresentou bons resultados } \\
\text { maternos e neonatais, mesmo quando a } \\
\text { transferência para o hospital foi } \\
\text { necessária. }\end{array}$ \\
\hline
\end{tabular}

0 MS tem criado e implementado estratégias que garantam às mulheres uma vivência mais positiva no trabalho de parto e parto, de forma segura, qualificada e humanizada, preconizando, por meio da Rede Cegonha, o uso de práticas de atenção à saúde baseadas em evidências científicas ${ }^{17}$. A partir dessas iniciativas, as mulheres estão refletindo sobre os benefícios do parto natural, o qual respeita a fisiologia do nascimento, e veem no domicílio um local adequado para essa experiência, pois proporciona liberdade e autonomia ${ }^{18}$. 
Conforme um estudo realizado no Rio de Janeiro, o parto humanizado, para as participantes da pesquisa, significa a não utilização de intervenções desnecessárias, a presença de acompanhantes de sua escolha e o respeito às suas vontades, pois para elas o fato de poder optar pelo tipo de parto que gostariam de ter significa reivindicar o direito de poder decidir sobre seus próprios corpos. Com a violência obstétrica, algumas mulheres têm procurado profissionais que garantam os seus direitos como cidadãs ${ }^{19}$.

A assistência humanizada durante o parto exige respeito, solidariedade, apoio, orientação, atuação livre de preconceitos, incentivo por parte do profissional e a utilização mínima de intervenções, pois desta forma o dano causado será o menor possível ${ }^{20}$.

Fatores que também contribuem para a humanização do parto são a presença de um acompanhante que compreenda a importância desse momento considerado tão especial e um ambiente acolhedor, garantindo, assim, que a mulher experimente menor estresse e ansiedade, trazendo segurança, conforto e tranquilidade, além de contribuir para a ausência de medo e para a progressão do trabalho de parto e parto 21 .

Nesse sentido, a enfermeira obstétrica contribui para uma assistência humanizada, na medida em que acredita na desmedicalização do parto ${ }^{22}$. Esse cuidado humanizado é de extrema importância para o sucesso nesse processo, pois a criação de vínculo entre o profissional, seu cliente e a família, bem como a consideração pelas escolhas, expectativas e cultura permitirão maior segurança e confiabilidade por parte dessas mulheres, devolvendo a ela o direito de ser mãe ${ }^{23}$.

\section{Práticas de cuidado das enfermeiras obstétricas} Cinco estudos ${ }^{9-13}$ revelaram como é a assistência das enfermeiras obstétricas durante o parto domiciliar planejado. Um desses estudos revela que as enfermeiras obstétricas permitem que as mulheres planejem seus partos, além de acolher e dar oportunidade para que exponham seus sentimentos, dúvidas e medos. Portanto, além do atendimento ser efetuado de forma humanizada, ele gera um relacionamento de confiança9.

A enfermeira obstétrica presta assistência ao parto sem distócia, realizando consultas, exames especializados, aplicação de anestésicos locais, suturas perineais e manobras de auxílio ao desprendimento fetal. Sua formação é voltada para aspectos sociais, psicológicos e humanos do parto, sem, no entanto, excluir o médico, mas apenas encaminhando a ele as situações nas quais sua atuação é realmente necessária ${ }^{12}$.

Outro estudo revela que, além da competência técnica e da organização do serviço, as enfermeiras obstétricas oferecem apoio emocional e sensibilidade diante da situação apresentada durante o trabalho de parto e parto, detectando, assim, precocemente as possíveis complicações que envolvem a transferência para o ambiente hospitalar ${ }^{10}$.

Há também, em um estudo, um relato que afirma que a profissional de enfermagem transmite sensação de segurança, atendimento focado na parturiente e cuidado humanizado, pois só realiza intervenções quando necessário, já que a legislação permite a realização de episiotomia, episiorrafia e aplicação de anestesia local ${ }^{13}$. Outro estudo mostra que o número de partos realizados por enfermeiras obstétricas subiu de menos de $10 \%$ para mais de $25 \%$ em 9 anos, e que os cuidados prestados por elas devem fortalecer cada vez mais as oportunidades de parto fisiológico ${ }^{11}$.

A enfermeira obstétrica atua para que a parturiente sinta maior segurança, pois além de proporcionar conforto e exercer a escuta, ela fornece atenção e cria vínculo, realizando ações baseadas nas necessidades levantadas. Por conseguinte, ela auxilia na redução da ansiedade e incentiva a mulher a ter mais coragem $^{20}$. As mulheres assistidas por enfermeiras obstétricas declaram uma experiência de satisfação em relação à sua atuação, principalmente na fase preparatória para o parto, pois no pré-natal a enfermeira tira todas as dúvidas, fazendo com que a mulher esteja mais preparada para cada situação que ocorrerá 24 .

A atenção humanizada deveria ser inerente à assistência obstétrica. No entanto, a violência obstétrica acontece desde a institucionalização do parto. Desse modo, para a OMS e o MS, a enfermeira obstétrica poderá transformar as condutas utilizadas atualmente, pois é considerada a categoria profissional mais preparada para mudar esse cenário e consolidar uma assistência segura durante esse processo $^{25-28}$.

Sendo assim, deve existir um relacionamento empático no cuidado a ser prestado durante o trabalho de parto e parto, pois a profissional de enfermagem deve ter paciência, respeito, disponibilidade para ouvir, delicadeza e levar em consideração os anseios, queixas e medos das parturientes, conscientizando-se dos sentimentos, necessidades e preocupações dos outros, buscando satisfazê-las.

Logo, um bom cuidado deve começar durante o pré-natal, com orientações sobre o estado gestacional, as modificações do corpo, os tipos de parto e as condutas que facilitam a participação ativa no processo de parturição. Desse modo, para prestar assistência à parturiente, os profissionais deverão ter conhecimento científico, raciocínio clínico e habilidades práticas, monitorando cuidadosamente o progresso do trabalho de 
parto e parto por meio do uso do partograma e da ausculta intermitente dos batimentos fetais. Nesse sentido, pode-se tomar decisões sobre condutas a adotar como o encaminhamento da mãe e seu recém-nascido para uma instituição que atenda em um nível mais complexo, caso surjam fatores de risco e complicações ${ }^{23}$.

Portanto, os partos realizados por enfermeiras obstétricas são seguros e eficazes, pois, ao entenderem esse evento como um processo fisiológico, utilizam-se do menor número de intervenções possíveis, melhorando os resultados tanto para a mãe quanto para o bebê. Além disso, utilizam-se de medidas não farmacológicas como: banho de aspersão com água morna, deambulação, movimentação pélvica e postura verticalizada para contribuir para a progressão do trabalho de parto ${ }^{22}$.

\section{Responsabilidade profissional}

Nessa categoria, apenas um artigo ${ }^{14}$ contribuiu para a presente revisão integrativa, o que demonstra a escassez de estudos sobre esse assunto. 0 estudo descreve a responsabilidade da enfermeira obstétrica por seus atos, uma vez que ela pode responder por todos os danos perante os órgãos regulamentadores, bem como frente à justiça, sujeitando-se à responsabilização civil, penal e éticoadministrativa $^{14}$.

Segundo o estudo, as enfermeiras obstétricas possuem apenas informações gerais sobre a sua atuação legal, o que não é suficiente para que ajam com segurança. No hospital, apesar de se sentir protegida pela instituição, a enfermeira responde judicialmente em conjunto com seu empregador. No parto domiciliar, ela responde sozinha por sua conduta, não sendo responsabilizada apenas se provar que o dano ocorreu devido a causas diversas de sua assistência. As enfermeiras obstétricas sentem-se abaladas com consequências morais ao cometer uma falha, pois sentem culpa e vergonha. Porém, foi revelada uma despreocupação com consequências judiciais ${ }^{14}$.

Sabe-se que a enfermeira obstétrica deve agir de acordo com os princípios éticos e morais, respeitando sempre o ser humano, informando a parturiente as alternativas de assistência ao parto, bem como quais são as práticas recomendadas pela OMS. Os riscos previsíveis devem ser evitados, pois a culpa profissional existirá mesmo quando, diante da possibilidade de antever e evitar um resultado negativo, o enfermeiro não o faz, resultando em dano ao cliente ${ }^{29}$.

O Código de Ética dos Profissionais de Enfermagem considera infração ética a ação, omissão ou conivência que implique em desobediência e/ou inobservância das disposições nele normatizadas. Juridicamente, a responsabilidade civil do enfermeiro nasce do dano, obrigando-o a responder pelos atos praticados, suportando as consequências deles advindas, e tendo a obrigação de restaurar, ressarcir ou reparar o prejuízo por meio do pagamento de indenização ${ }^{30}$.

0 enfermeiro obstetra não pode garantir o desfecho do trabalho de parto e parto. Porém, pode ser cuidadoso e zeloso, de modo que seja evitada a exposição da mulher e do bebê a riscos desnecessários, já que existe a possibilidade de intercorrências repentinas e imprevisíveis e, dessa forma, o profissional deve dedicar atenção, ter cautela para agir e tomar as decisões com rapidez e habilidade.

Ao prestar o cuidado durante o trabalho de parto domiciliar, o enfermeiro deve evitar tomar decisões pouco criteriosas. Elas podem resultar em um curso inevitável e em sua consequente responsabilização criminal, pois, no âmbito da responsabilidade penal, esse profissional poderá responder por situações que causem danos aos clientes e à sociedade, bem como pelo exercício ilegal da profissão. Dessa maneira, constitui contravenção com pena que pode ser desde prisão simples ou multa até exercer a profissão sem preencher as condições determinadas por lei, ou seja, sem a devida capacidade legal.

Um dos itens que contribuem para a prestação da assistência de enfermagem de forma ética e segura é o fato do enfermeiro ter conhecimento sobre os aspectos legais, direitos e obrigações do próprio exercício profissional. Dessa forma, ele deve voltar sua atenção para os limites da competência, agindo rigorosamente dentro do que a sua legislação profissional lhe autoriza realizar ${ }^{29}$.

\section{Desfecho do parto domiciliar}

Sobre essa temática, foram encontrados quatro estudos $^{9-10,15,16}$. 0 primeiro estudo afirma que memórias positivas de parto domiciliar relatadas por parturientes torna o processo fisiológico do nascimento um evento natural e repleto de confiança9.

Outro estudo demonstrou que, dentre as 102 parturientes assistidas por enfermeiras em domicílio, a transferência materna para ambiente hospitalar foi de $11 \%$, que a transferência para unidade neonatal foi para apenas um bebê, mas que não foi relacionada à assistência prestada, e que a necessidade de cesariana foi para nove mulheres. Houve baixa porcentagem de amniotomia, a duração do trabalho de parto foi menor e a maioria optou por posição não litotômica ${ }^{15}$.

Ainda nesse sentido, outra investigação com 100 mulheres assistidas em parto domiciliar, apontou que 11 foram transferidas para hospitais precocemente, objetivando, assim, minimizar eventuais riscos maternos e fetais. Quanto ao recém-nascido, não houve nenhuma transferência para Unidade de Terapia Intensiva Neonatal, e a opção de grande parte das mulheres por serem transferidas para 
o hospital e serem atendidas pelos médicos do pré-natal, podem ser atribuídas às relações de confiança que já haviam estabelecido com eles. Outro motivo foi devido ao receio de serem discriminadas por profissionais de saúde que fazem restrições ao parto domiciliar planejado, embora posteriormente as transferências tenham gerado insatisfação ${ }^{16}$.

Apesar do que comumente se pensa, o domicílio é um ambiente positivo e que apresenta resultados favoráveis para a evolução do trabalho de parto e parto, já que, além de permitir a presença de familiares, respeita os direitos da mulher, reduz as intervenções e atende às necessidades psicológicas, emocionais e sociais da parturiente. Portanto, 0 parto domiciliar planejado não aumentou os riscos de mortalidade e morbidade materna e perinatal, sendo esse índice inclusive menor do que em ambiente hospitalar ${ }^{10}$.

Um estudo demonstra que algumas mulheres optaram pelo parto domiciliar planejado justamente para poderem exercer seus direitos reprodutivos e, após vivenciarem essa experiência, sentiram-se satisfeitas, pois além de terem sido atendidas de forma respeitosa e confiante, não foram submetidas à episiotomia e o bebê não foi exposto a nenhuma intervenção. Portanto, os relatos de mulheres que optaram por essa forma de parir demonstram realização pessoal plena e deslumbramento ${ }^{19}$.

A Associação Brasileira de Obstetrizes e Enfermeiros Obstetras afirma que o parto de risco habitual, quando assistido por enfermeira obstétrica, apresenta vantagens quanto à redução do número de intervenções e maior satisfação das parturientes ${ }^{31}$. Dessa forma, o parto humanizado, além de desenvolver na mulher uma percepção positiva desse processo, reduz a necessidade de intervenções, a taxa de complicações e de cesariana, o uso de analgesia, a duração do trabalho de parto, o tempo de internação, incentiva o aleitamento materno e proporciona menor risco de depressão pósparto ${ }^{21,32}$.

As tecnologias não invasivas de cuidado utilizadas pela enfermeira obstétrica alcançam resultados similares ou melhores do que os dos médicos, pois seus cuidados têm sido associados a menores índices de intervenções como a cesariana e o uso de fórceps e ao fato dos recém-nascidos obterem melhores índices de apgar do primeiro ao quinto minuto 22 .

Dessa forma, mulheres declaram que o parto domiciliar é melhor por diversos motivos. Dentre eles, maior rapidez, menos intervenções invasivas e maior liberdade de movimentação, comprovando a satisfação que tiveram com o cuidado recebido e remontando às críticas ao modelo de assistência ao parto presente nas maternidades brasileiras. As entrevistadas também demonstram frustração com a experiência vivenciada durante o parto hospitalar, em comparação ao domiciliar ${ }^{18}$.

\section{CONCLUSÃO}

A partir dos resultados obtidos, foi possível identificar as práticas de cuidado realizadas pela enfermeira obstétrica no parto domiciliar planejado. Essa profissional atua não só com competência técnica, mas também priorizando o aspecto psicológico, emocional e fisiológico do processo de parto, realizando intervenções sem efeitos colaterais e utilizando-se minimamente de procedimentos invasivos, prestando assim o cuidado humanizado preconizado pelos órgãos governamentais.

Apesar de a enfermeira obstétrica estar apta legalmente para o atendimento ao parto domiciliar planejado, ela deve ter o conhecimento necessário para que não somente atue com responsabilidade profissional conforme a legislação permite, mas para que também possa atuar até onde sua formação possibilite, visando proporcionar um cuidado seguro e livre de danos à cliente. Desse modo, devido ao fato de apenas um artigo mencionar a temática da responsabilidade profissional, e esse ser um assunto de grande importância na atuação da enfermeira obstétrica no parto domiciliar planejado, sugere-se novas pesquisas a respeito do tema.

Este estudo demonstrou a escassez de produções sobre a atuação da enfermeira obstétrica na assistência ao parto domiciliar planejado, o que figura também como uma limitação deste estudo que, apesar disso, verificou que as práticas de cuidado realizadas pela enfermeira obstétrica contribuem para um desfecho favorável do trabalho de parto e parto e para a satisfação das parturientes.

\section{REFERÊNCIAS}

1. Sanfelice CFO, Abbud FSF, Pregnolatto OS, Silva MG, Shimo AKK. Do parto institucionalizado ao parto domiciliar. Rev RENE. [Internet]. 2014 [citado em 18 set 2017]; 15(2):362-70. Disponível em: http://www.revistarene.ufc.br/revista/index.php/r evista/article/viewFile/1561/pdf

2. Moura FMJSP, Crizostomo CD, Nery IS, Mendonça RCM, Araújo OD, Rocha SS. A humanização e a assistência de enfermagem ao parto normal. Rev Bras Enferm. [Internet]. 2007 [citado em 18 set 2017]; 60(4):452-5. Disponível em: http://www.scielo.br/scielo.php?script=sci_arttext \&pid=S0034-3371672007000400018

3. Ministério da Saúde (Br). Humanização do parto e do nascimento. Brasília, DF: Ministério da Saúde; 2014. 465p. (Caderno HumanizaSUS; v.4)

4. Conselho Federal de Enfermagem (Brasil). Resolução COFEN no 0516/2016. Normatiza a atuação e a responsabilidade do Enfermeiro, Enfermeiro Obstetra e Obstetriz na assistência às gestantes, parturientes, puérperas e recém-nascidos nos Serviços de Obstetrícia, Centros de Parto Normal e/ou Casas de Parto e outros locais onde ocorra essa assistência; estabelece critérios para 
registro de títulos de Enfermeiro Obstetra e Obstetriz no âmbito do Sistema COFEN/Conselhos Regionais de Enfermagem, e dá outras providências [Internet]. Brasília, DF: COFEN; 2016 [citado em 08 abr 2017]. Disponível em: http://www.cofen.gov.br/resolucao-cofen-no05162016_41989.html

5. Conselho Federal de Enfermagem (Brasil). Nota oficial no 001/2012/ASCOM. Brasília, DF: COFEN; 2012.

6. Silva TF, Costa GAB, Pereira ALF. Cuidados de enfermagem obstétrica no parto normal. Cogitare Enferm. [Internet]. 2011[citado em 18 set 2017]; 16(1):82-7. Disponível em: http://ojs.c3sl.ufpr.br/ojs2/index.php/cogitare/art icle/view/21116/13942

7. Sanfelice CFO, Shimo AKK. Parto domiciliar: avanço ou retrocesso? Rev Gaúcha Enferm. [Internet]. 2014 [citado em 18 set 2017]; 35(1):15760. Disponível em: http://www.scielo.br/scielo.php?pid=S198314472 014000100157\&script=sci_arttext\&tlng=pt

8. Ganong LH. Revisão integrativa na pesquisa de enfermagem. Rev Nursing Health. 1987; 10(1):1-11. 9. Medeiros RMK, Santos IMM, Silva LR. A escolha pelo parto domiciliar: história de vida de mulheres que vivenciaram esta experiência. Esc Anna Nery Rev Enferm. [Internet]. 2008 [citado em 18 set 2017]; 12(4):765-72. Disponível em: http://www.scielo.br/pdf/ean/v12n4/v12n4a22.p df

10. Frank TC, Pelloso SM. A percepção dos profissionais sobre a assistência ao parto domiciliar planejado. Rev Gaúcha Enferm. [Internet]. 2013 [citado em 18 set 2017]; 31(1):22-9. Disponível em: http://www.scielo.br/pdf/rgenf/v34n1/03.pdf

11. Offerhaus PM, Jonge A, Pal-de-Bruin KM, Hukkelhoven CWPM, Scheepers PLH, Lagro-Janssen ALM. Change in primary midwife-led care in the Netherlands in 2000-2008: a descriptive study of caesarean sections and other interventions among 789,795 low risk births. Midwifery. [Internet]. 2013 [citado em 18 set 2017]; 30(5):560-6. Disponível em:

http://www.midwiferyjournal.com/article/S02666138(13)00186-1/abstract?cc=y

12. Garcia SAL, Lippi GUG, Garcia SAL. O parto assistido por enfermeira obstetra: perspectivas e controvérsias. RBPS [Internet]. 2010 [citado em 18 set 2017]; 23(4):380-8. Disponível em: http://www.unifor.br/images/pdfs/rbps/artigo11_ 2010.4.pdf

13. Souza RM, Soares LS, Quitete JB. Parto natural domiciliar: um poder da natureza feminina e um desafio para a enfermagem obstétrica. Rev Pesqui Cuid Fundam. [Internet]. 2014 [citado em 18 set 2017]; 6(1):118-31. Disponível em: http://www.seer.unirio.br/index.php/cuidadofund amental/article/view/2260/pdf_1100

14. Winck DR, Bruggemann OM, Monticelli M. A responsabilidade profissional na assistência ao parto: discursos de enfermeiras obstétricas. Esc Anna Nery Rev Enferm. [Internet]. 2012 [citado em 18 set 2017]; 16(2):363-70. Disponível em: http://www.scielo.br/scielo.php?script=sci_arttext \&pid=S1414-

81452012000200022\&lng=pt\&tlng=es

15. Koettker JG, Brüggemann OM, Dufloth RM, Knobel R, Monticelli M. Resultado de partos domiciliares atendidos por enfermeiras de 2005 a 2009 em Florianópolis, SC. 2012. Rev Saúde Pública. [Internet]. 2012 [citado em 18 set 2017]; 46(4):747$50 . \quad$ Disponível em: http://www.scielo.br/scielo.php?script=sci_arttext \&pid=S0034-89102012000400020\&lng=pt

16. Koettker JG., Bruggemann OM, Dufloth RM. Partos domiciliares planejados assistidos por enfermeiras obstétricas: transferências maternas e neonatais. Rev Esc Enferm USP. [Internet]. 2013 [citado em 18 set 2017]; 47(1):15-21. Disponível em:

http://www.scielo.br/scielo.php?script=sci_arttext \&pid=S0080-

62342013000100002\&lng=pt\&nrm=iso\&tlng=en 17. Ministério da Saúde (Br). Portaria $\mathrm{n}^{\circ}$ 1.459, de 24 de junho de 2011. Institui no âmbito do Sistema Único de Saúde - SUS - a Rede Cegonha. Brasília, DF: Ministério da Saúde; 2011.

18. Feyer ISS, Monticelli M, Boehs, AE, Santos EKA. Rituais de cuidado realizados pelas famílias na preparação para a vivência do parto domiciliar planejado. Rev Bras Enferm. [Internet]. 2013 [citado em 18 set 2017]; 66(6):879-86. Disponível em: http://www.scielo.br/pdf/reben/v66n6/11.pdf 19. Quitete JB. Atribuindo significados as enfermeiras obstétricas: uma construção social sob a ótica das usuárias na perspectiva do interacionismo simbólico. [Tese]. Rio de Janeiro: Faculdade de Enfermagem, Universidade do Estado do Rio de Janeiro; 2015.

20. Almeida OSC, Gama ER, Bahiana PM. Humanização do parto: a atuação dos enfermeiros. Rev Enferm Contemp. [Internet]. 2015 [acesso em 18 set 2017]; 4(1):79-90. Disponível em: https://www5.bahiana.edu.br/index.php/enferma gem/article/view/456

21. Dodou HD, Guerreiro EM, Rodrigues DP, Lago PN, Guedes MVC, Mesquita NS. A contribuição do acompanhante para a humanização do parto e nascimento: percepções de puérperas. Esc Anna Nery Rev Enferm. [Internet]. 2014 [citado em 18 set 2017]; 18(2):262-9. Disponível em: http://www.scielo.br/pdf/ean/v18n2/1414-8145ean-18-02-0262.pdf

22. Reis CSC, Souza DOM, Nogueira MFH, Progianti JM, Vargens OMC. Análise de partos acompanhados por enfermeiras obstétricas na perspectiva da humanização do parto e nascimento. Rev Pesqui Cuid Fundam. [Internet]. 2016 [citado em 18 set 2017]; 8(4):4972-9. Disponível em: http://www.seer.unirio.br/index.php/cuidadofund amental/article/view/3966/pdf_1

23. Versiani CC, Barbieri M, Gabrielloni MC, Fustinoni SM. Significado de parto humanizado para gestantes. Rev Pesqui Cuid Fundam. [Internet]. 2015 [citado em 18 set 2017]; 7(1):1927-35. Disponível em:

http://www.redalyc.org/pdf/5057/50575094501 7.pdf

24. Feyer ISS, Monticelli M, Volkmer C, Burigo RA. Publicações científicas brasileiras de enfermeiras obstétricas sobre parto domiciliar: revisão sistemática de literatura. Texto \& Contexto Enferm. [Internet]. 2013 [citado em 18 set 2017]; 22(1):247$56 . \quad$ Disponível em: http://www.scielo.br/pdf/tce/v22n1/pt_30.pdf

25. Presidência da República (Brasil). Decreto $\mathrm{n}^{0}$ 94.406, de 08 de junho de 1987. Regulamenta a Lei 
no 7.498, de 25 de junho de 1986, que dispõe sobre o exercício da enfermagem, e dá outras providências [Internet]. Brasília, DF; 1987 [citado em 08 abr 2018]. Disponível

http://www.cofen.gov.br/decreto-n-

9440687_4173.html

26. Presidência da República (Brasil). Lei no 7.498, de 25 de junho de 1986. Dispõe sobre a regulamentação do exercício da enfermagem, e dá outras providências [Internet]. Brasília, DF; 1986 [citado em 08 abr 2018]. Disponível em: http://www.cofen.gov.br/lei-n-749886-de-25-dejunho-de-1986_4161.html

27. Organização Mundial da Saúde. Maternidade segura. Assistência ao parto normal: um guia prático. Genebra: OMS; 1996. 93p.

28. Silva MG, Marcelino MC, Rodrigues LSP, Toro RC, Shimo AKK. Violência obstétrica na visão de enfermeiras obstetras. Rev RENE. [Internet]. 2014 [citado em 18 set 2017]; 15(4):720-8. Disponível em:

http://www.periodicos.ufc.br/rene/article/view/1 $121 / 1079$

29. Winck DR., Bruggemann OM. Responsabilidade legal do enfermeiro em obstetrícia. Rev Bras Enferm. [Internet]. 2010 [citado em 18 set 2017]; 63(3):4649. Disponível

em:

http://www.scielo.br/scielo.php?script=sci_arttext \&lng=pt\&tlng=pt\&pid=S0034-

71672010000300019
30. Conselho Federal de Enfermagem (Brasil). Código de Ética: Resolução COFEN 240/2000. Brasília, DF: COFEN; 2000.

31. Associação Brasileira de Obstetrizes e Enfermeiros Obstetras. Assistência por enfermeiras(os) obstétricas(os) e obstetrizes tem respaldo na lei [Internet]. [S.l.]: ABENFO; $25 \mathrm{abr}$ 2016 [citado em 30 maio 2017]. Disponível em: http://abenfo.wix.com/meusite\#!Assistencia-porenfermeirasos-obstetricasos-e-obstetrizes-temrespaldo-na-

lei/c193z/571e731e0cf2dcaa530e7383

32. Esteves TMB, Daumas RP, Oliveira MIC, Andrade CAF, Leite IC. Fatores associados a amamentação na primeira hora de vida: revisão sistemática. Rev Saúde Pública. [Internet]. 2014 [citado em 18 set 2017]; 48(4):697-708. Disponível em: http://www.revistas.usp.br/rsp/article/view/857 20

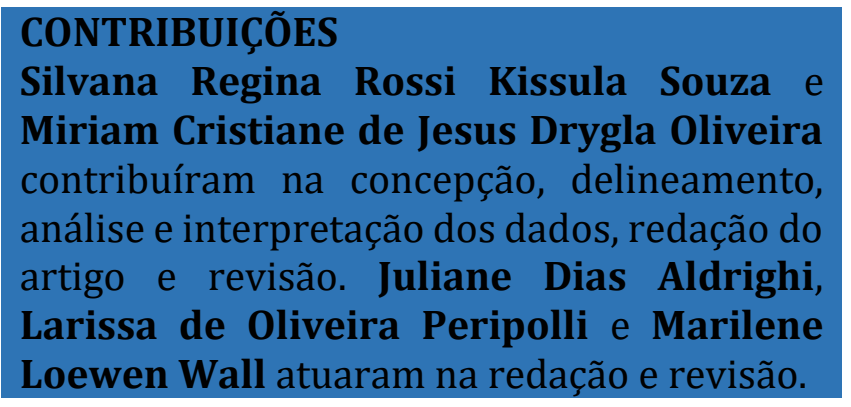

\footnotetext{
Como citar este artigo (Vancouver)

Souza SRRK, Oliveira MCJD, Aldrighi JD, Peripolli LO, Wall ML. A enfermeira obstétrica no cuidado ao parto domiciliar planejado: revisão integrativa. REFACS [Internet]. 2019 [citado em inserir dia, mês e ano de acesso]; 7(3):357-365. Disponível em: inserir link de acesso. DOI: inserir link do DOI.

\section{Como citar este artigo (ABNT)}

SOUZA, S. R. R. K.; OLIVEIRA, M. C. J. D.; ALDRIGHI, J. D.; PERIPOLLI, L. O.; WALL, M. L. A enfermeira obstétrica no cuidado ao parto domiciliar planejado: revisão integrativa. REFACS, Uberaba, MG, v. 7, n. 3, p. 357-365, 2019. Disponível em: inserir link de acesso. Acesso em: inserir dia, mês e ano de acesso. DOI: inserir link do DOI.

Como citar este artigo (APA)

Souza, S.R.R.K., Oliveira, M.C.J.D., Aldrighi, J.D., Peripolli, L.O. \& Wall, M.L. (2019). A enfermeira obstétrica no cuidado ao parto domiciliar planejado: revisão integrativa. REFACS, 7(3), 357-365. Recuperado em: inserir dia, mês e ano de acesso de inserir link de acesso. DOI: inserir link do DOI.
} 